\title{
Ventilator circuits, humidification and ventilator-associated pneumonia
}

\author{
DEAN HESS PhD RRT \\ Harvard Medical School and Massachusetts General Hospital, Boston, Massachusetts, USA
}

D HESS. Ventilator circuits, humidification and ventilator-associated pneumonia. Can Respir J 1996;3(6):397402.

Technical issues in the care of mechanically ventilated patients include those related to the ventilator circuit, humidification and ventilator-associated pneumonia. Principal issues related to ventilator circuits include leaks and compression volume. Circuit compression volume affects delivered tidal volume as well as measurements of autopositive end-expiratory pressure and mixed expired $\mathrm{PCO}_{2}$. Resistance through the ventilator circuit contributes to patient-ventilator dyssynchrony during assisted modes of mechanical ventilation. Adequate humidification of inspired gas is necessary to prevent heat and moisture loss. Common methods of humidification of inspired gas during mechanical ventilation include use of active heated humidifiers and passive artificial noses. Artificial noses are less effective than active humidifiers and are best suited to short term use. With active humidifiers, the circuit can be heated to avoid condensate formation. However, care must be exercised when heated circuits are used to avoid delivery of a low relative humidity and subsequent drying of secretions in the artificial airway. Although pneumonia is a complication of mechanical ventilation, these pneumonias are usually the result of aspiration of pharyngeal secretions and are seldom related to the ventilator circuit. Ventilator circuits do not need to be changed more frequently than weekly for infection control purposes, and the incidence of ventilatorassociated pneumonia may be greater with more frequent circuit changes.

Key Words: Humidification, Ventilator-associated pneumonia Ventilator circuits

\section{Les circuits des ventilateurs, l'humidification et la pneumonie associée au ventilateur}

RÉSUMÉ : Les aspects techniques de la prise en charge des patients ventilés mécaniquement comprennent ceux qui ont rapport au circuit du ventilateur, à l'humidification et à la pneumonie associée au ventilateur. Les aspects principaux concernant le circuit du ventilateur comprennent les fuites et le volume de compression. Le volume de compression du circuit affecte le volume courant fourni aussi bien que les mesures d'auto-pression expiratoire positive (PEEP) et de la $P \mathrm{PO}_{2}$ expirée. La résistance générée à travers le circuit du ventilateur contribue à une désynchronisation patient-ventilateur dans les modes assistés de la ventilation mécanique. Une humidification adéquate du gaz inspiré est nécessaire pour prévenir une perte de chaleur et d'humidité. Les méthodes couramment employées pour humidifier l'air inspiré lors de la ventilation mécanique comprennent l'utilisation d'humidificateurs chauffants et de nez artificiels passifs. Les nez artificiels sont moins efficaces que les humidificateurs chauffants et sont mieux adaptés à un usage à court terme. Avec les humidificateurs chauffants, le circuit peut être chauffé pour éviter la formation de condensation. Cependant, quand on utilise des circuits chauffés, on doit faire attention à ne pas faire baisser humidité relative qui entraînera un assèchement des secrétions dans le tube endotrachéal. Bien que les pneumonies soit une complication de la ventilation mécanique, celles-ci résultent souvent d'une aspiration des sécrétions pharyngées et sont rarement liées au circuit du ventilateur. Il n'est pas nécessaire de changer le circuit du ventilateur plus d'une fois par semaine pour des raisons de contrôle des infections; l'incidence des pneumonies associées au ventilateur pourrait même être plus élevée lorsque les changements du circuit sont plus fréquents.

Correspondence and reprints: Dr Dean Hess, Respiratory Care Ellison 401, Massachusetts General Hospital, Boston, MA 02114, USA. Telephone 617-724-4480, fax 617-724-4495, e-mail hessd@a1.mgh.harvard.edu 
$\mathrm{C}$ are of mechanically ventilated patients requires attention to both physiological and technical issues. The outcome from mechanical ventilation is often affected by the interface between the patient and the ventilator. To deliver an adequate tidal volume (VT), this interface must be unobstructed, leak-free, and have minimal compliance and compressible volume.

\section{THE VENTILATOR CIRCUIT}

The ventilator circuit delivers gas to the patient and conditions the inspired gases by filtering and humidification. Principal issues related to ventilator circuits include leaks (Table 1) and compression volume. Compression volume within the circuit is determined by the volume of the circuit, the compliance (elasticity) of the tubing material and the ventilation pressure. Circuit compression volume does not reach the patient and becomes clinically important with high pressures and low VTs. The volume that leaves the expiration valve of the ventilator includes the expired volume from the patient and the volume of gas compressed in the ventilator circuit. Unless volume is measured directly at the patient's airway, the expired volume displayed by the ventilator overestimates the patient's actual VT by the amount of the compressible volume. Some current microprocessor ventilators correct measured volume for circuit compression volume.

Compressible volume can be calculated by multiplying the compression factor by the airway pressure. The compression factor is about 2 to $4 \mathrm{~mL} / \mathrm{cm} \mathrm{H}_{2} \mathrm{O}$ for circuits with a humidifier. The delivered VT is the volume leaving the expiration valve minus the compression volume:

$$
\mathrm{VT}=\mathrm{VTexp}-(\text { factor })(\mathrm{PIP}-\mathrm{PEEP})
$$

where VTexp is the volume leaving the expiration valve, VT is tidal volume corrected for compression, PIP is peak inspiratory pressure and PEEP is positive end-expiratory pressure.

Consideration of compression volume is important for several reasons. Most important, it decreases the delivered VT. Failure to consider compression volume results in overestimation of lung compliance. Auto-PEEP measurements are also affected by circuit compression volume, as follows:

$$
\text { auto-PEEP }=[(\mathrm{Crs}+\mathrm{Cpc}) / \mathrm{Crs}](\text { estimated auto-PEEP })
$$

where $\mathrm{Crs}$ is the compliance of the respiratory system, $\mathrm{Cpc}$ is the compliance of the circuit (ie, the compression factor) and estimated auto-PEEP is the value that is measured. Compression volume also affects the measurement of mixed expired carbon dioxide tension $\left(P \overline{\mathrm{E}} \mathrm{CO}_{2}\right)$. Because the inspired gas is compressed, it contributes a volume in excess of VT, which dilutes the mixed expired $\mathrm{PCO}_{2}$; this may be corrected by applying the following equation:

$$
P \overline{\mathrm{E}} \mathrm{CO}_{2}=\left(P \exp \mathrm{CO}_{2}\right)(\mathrm{VT} \exp / \mathrm{VT})
$$

where $P \overline{\mathrm{E}} \mathrm{CO}_{2}$ is the true mixed expired $P_{\mathrm{CO}}$ and $P \operatorname{expCO} 2$ is measured mixed expired $\mathrm{PCO}_{2}$ (including gas compressed in the ventilator circuit). This correction is important for dead space calculations. Compression volume does not affect
TABLE 1 Identification of leaks in the ventilator circuit

\begin{tabular}{ll}
\hline System leak: & Volume into circuit $>$ volume leaving circuit \\
Circuit leak: & Volume into circuit $>$ volume into patient \\
Patient leak: & Volume into patient $>$ volume out of patient \\
Disconnect: & Loss of airway pressure and expired volume \\
\hline
\end{tabular}

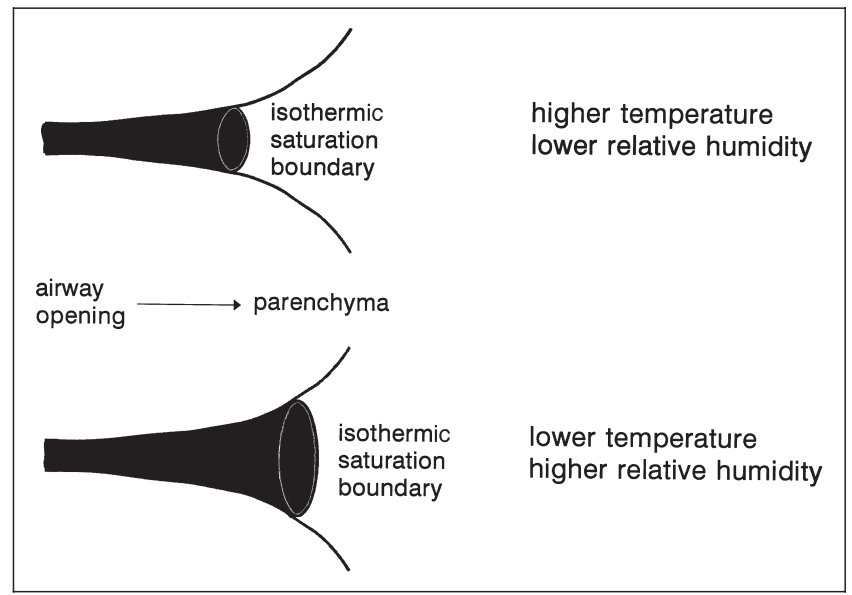

Figure 1) Top The isothermic saturation boundary may be in the endotracheal tube with high temperature and low relative humidity; this may produce crusting of secretions in the endotracheal tube and airway obstruction in spite of an adequate absolute humidity. Bottom With a lower temperature and higher relative humidity (but lower absolute humidity), the isothermic saturation boundary is in the lower respiratory tract; this prevents crusting of secretions in the endotracheal tube but increases the amount of humidity that must be added by the respiratory tract - this can cause drying of secretions in the lower respiratory tract

measurements of rates of oxygen consumption and carbon dioxide elimination.

During assisted modes of ventilation, the resistance through the ventilator circuit may contribute to patient-ventilator dyssynchrony. The inspiratory work of breathing due to circuit resistance is a function of the inspiratory flow. When this is coupled to the resistance through an endotracheal tube, the imposed work may be clinically important at high flows. The effects of inspiratory circuit resistance becomes important during assisted and spontaneous modes of breathing and can be decreased by triggering at the proximal airway. The resistance through the expiratory limb of the circuit is primarily that due to the expiration valve. Mushroom and scissor valves have significant expiratory resistance. Current generation ventilators use an expiration valve with a large electrically controlled diaphragm that produces a more consistent circuit pressure regardless of flow. Excessive expiratory circuit resistance can prolong expiration and produce auto-PEEP.

\section{HUMIDIFICATION}

Inspired gases are conditioned in the airway so that they are fully saturated with water at body temperature by the time they reach the alveoli $\left(37^{\circ} \mathrm{C}, 100 \%\right.$ relative humidity, $44 \mathrm{mg} / \mathrm{L}$ absolute humidity, $47 \mathrm{mmHg}$ water vapour pres- 


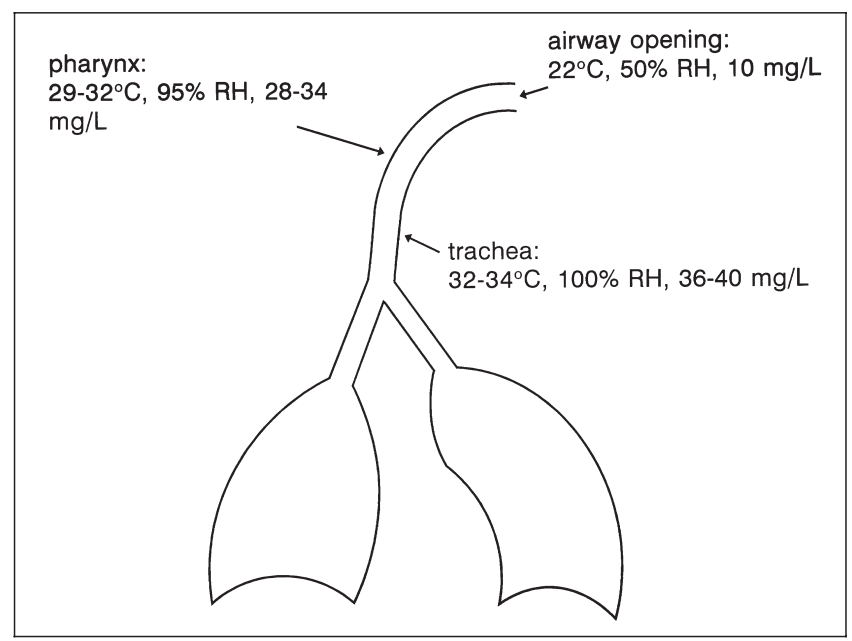

Figure 2) Temperature, relative humidity $(\mathrm{RH})$ and absolute humidity levels at three sites in the respiratory tract. The output of any therapeutic gas delivery system should match the normal conditions at that point of entry into the respiratory system

sure). The point in the airway at which the inspired gases reach body temperature and humidity is the isothermic saturation boundary (ISB), and below this point there is no fluctuation of temperature and humidity. The ISB is normally just below the carina. Above the ISB, heat and humidity are added to the inspired gases, and heat and humidity are extracted from the expired gases. Much of this portion of the airway is bypassed in patients with an artificial airway (endotracheal or tracheostomy tube), necessitating the use of external humidifying apparatus. Under normal conditions, about $250 \mathrm{~mL}$ of water is lost from the lungs each day to humidify the inspired gases.

The physiological effects of inadequate humidity can be due to heat loss or to moisture loss. Although heat loss from the respiratory tract occurs due to humidification, mechanisms other than respiration are usually more important for temperature homeostasis. Moisture loss from the respiratory tract results in drying of secretions, decreased compliance, decreased surfactant activity, atelectasis and hypoxemia.

Both absolute humidity and relative humidity are important (Figure 1). Absolute humidity determines the amount of water that must be added to the inspired gas, whereas relative humidity determines the site in the respiratory tract that adds the water. If absolute humidity is adequate but relative humidity is low, the ISB may be in the endotracheal tube. This could result in crusting of secretions in the endotracheal tube. On the other hand, if the relative humidity is high but absolute humidity is low, the ISB is lower in the respiratory tract. This results in greater water uptake from the lower respiratory tract, which could make secretion clearance more difficult.

Over-humidification is possible only if the temperature of the inspired gases is greater that $37^{\circ} \mathrm{C}$ and the absolute humidity is greater than $44 \mathrm{mg} / \mathrm{L}$. This is unlikely with heated humidifiers and usually will not occur in a device that does not produce an aerosol. Although it is difficult to produce excessive humidification with a heated humidifier, humidification of the inspired gases (during mechanical ventilation)
TABLE 2

Brief comparison of different types of humidifiers used with critically ill patients

Saline instillation

Simple and low cost; risk of contamination; aids removal of thick tenacious secretions, but should not be used routinely Heated humidifier

Efficient but expensive; condensation in circuit unless circuit heated; maintains body temperature; contributes to compression volume of circuit

Nebulizer

Simple and efficient; condensation in circuit; contributes to compression volume; may contribute to water load to patient; aids removal of secretions; airway cooling (unless heated); airway contamination

Artificial nose

Convenient and requires no external power source; marginal efficiency of some devices; adds dead space and resistance; serves as filter; may clog with secretions

decreases the insensible water loss that normally occurs during breathing. Failure to consider this could result in a positive water balance $(250 \mathrm{~mL} /$ day $)$. With humidification systems, significant heat gain is unlikely and tracheal injury due to high temperature output of a humidifier is an infrequent occurrence. Because the specific heat of gas is low, it is difficult to transfer significant amounts of heat to cause tracheal burns without an aerosol. In hypothermic patients, super-warming of inspired gases has little effect in the facilitation of core rewarming. Breathing gases warmed and humidified to normal body conditions, however, complements other rewarming techniques because it prevents further heat loss from the respiratory tract.

The output of any therapeutic gas delivery system should match the normal conditions at that point of entry into the respiratory system (Figure 2). If the temperature and humidity are less than this, a humidity deficit is produced; if the temperature and humidity are greater than this, fluid overload and patient discomfort may occur. Inspired gases that bypass the upper respiratory tract (eg, endotracheal tubes and tracheostomy tubes) should be heated to $32^{\circ} \mathrm{C}$ to $34^{\circ} \mathrm{C}$ at $95 \%$ to $100 \%$ relative humidity.

Techniques to humidify the lower respiratory tract are summarized in Table 2. Heated humidifiers are capable of providing a relative humidity of nearly $100 \%$ at temperatures near body temperature. Specific devices include the passover, cascade, wick and vapour phase humidifiers. The water level in the reservoir of a humidifier can be maintained by manually adding water, adding water from a bag attached to the humidifier or by a continuous-feed system that keeps the water level constant. Closed-feed systems avoid interruption of ventilation to fill the humidifier. Continuous-feed systems avoid fluctuations in the temperature of delivered gas and maintain a low compression volume. Many heated humidifier systems are servo-controlled with a thermistor at the proximal airway to maintain the desired gas delivery temperature. Cooling of the gas between the humidifier and the patient 


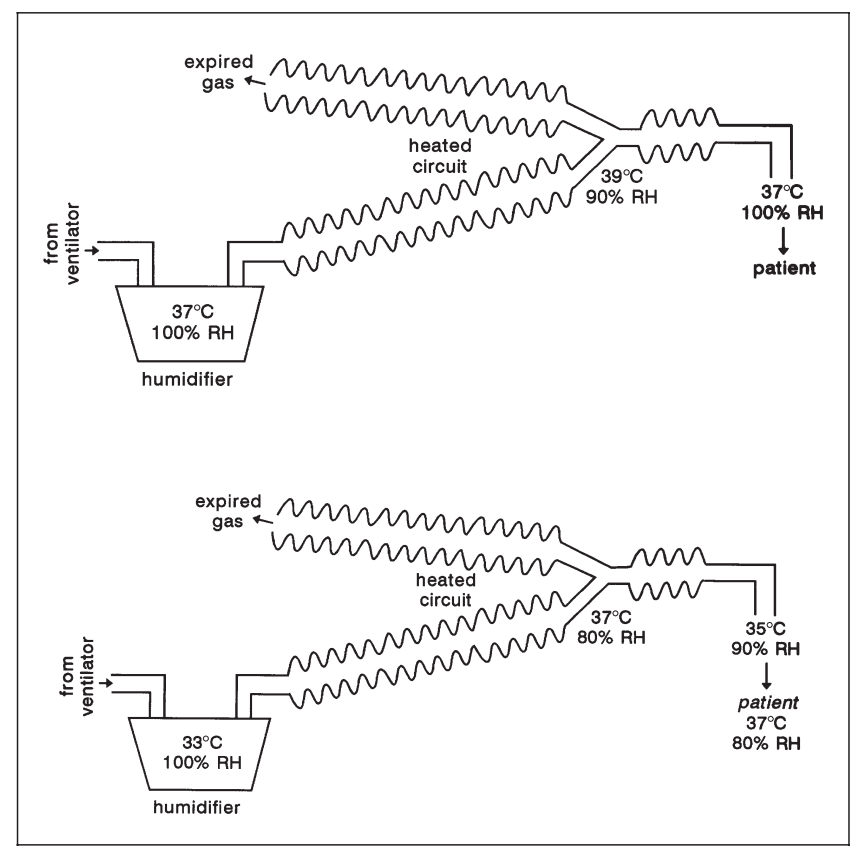

Figure 3) Top The output of the humidifier is $37^{\circ} \mathrm{C}$ and $100 \%$ relative humidity $(\mathrm{RH})$. Condensation in the circuit is avoided by heating the circuit to $39^{\circ} \mathrm{C}$, which reduces $\mathrm{RH}$ to $90 \%$. The gas cools to $37^{\circ} \mathrm{C}$ between the unheated $Y$-piece and the patient, raising the RH to $100 \%$. Bottom The circuit also remains dry if the output of the humidifier is set at $33^{\circ} \mathrm{C}$ and the proximal airway temperature is set at $37^{\circ} \mathrm{C}$. In this case, however, the $\mathrm{RH}$ delivered is reduced, which can cause crusting of secretions in the endotracheal tube

results in condensation (rain-out), which should be collected in a water trap and removed aseptically.

The circuit that carries gas from the humidifier to the patient can be heated. This prevents a temperature drop in the circuit, and a more precise gas temperature can be delivered. If the temperature of the circuit is greater than the temperature of the gas leaving the humidifier, then the relative humidity of the gas will drop and the circuit will remain dry. The decrease in relative humidity that can occur with heated circuits may produce drying of secretions in the endotracheal tube (Figure 3). If condensate is present in the circuit near the patient, this suggests that relative humidity is $100 \%$ and drying of secretions in the endotracheal tube is avoided. If the humidifier chamber temperature is set at $37^{\circ} \mathrm{C}$ and the circuit temperature is set at $39^{\circ} \mathrm{C}$, then the relative humidity will drop to about $90 \%$ and the circuit will remain dry (Figure 4). As the gas cools between the Y-piece and the patient (approximately $2^{\circ} \mathrm{C}$ ), the gas should enter the endotracheal tube at $37^{\circ} \mathrm{C}$ and $100 \%$ relative humidity.

Artificial noses passively humidify the inspired gases by collecting the patient's expired heat and moisture and returning them during the following inspiration (Figure 5). These devices are attractive alternatives to heated humidifiers because of their passive operation and their relatively low cost. Important considerations in the performance of artificial noses are their humidity output, dead space, flow resistance and cost. Some artificial noses provide greater than $30 \mathrm{mg} / \mathrm{L}$ of water to the airway at minute ventilation less than

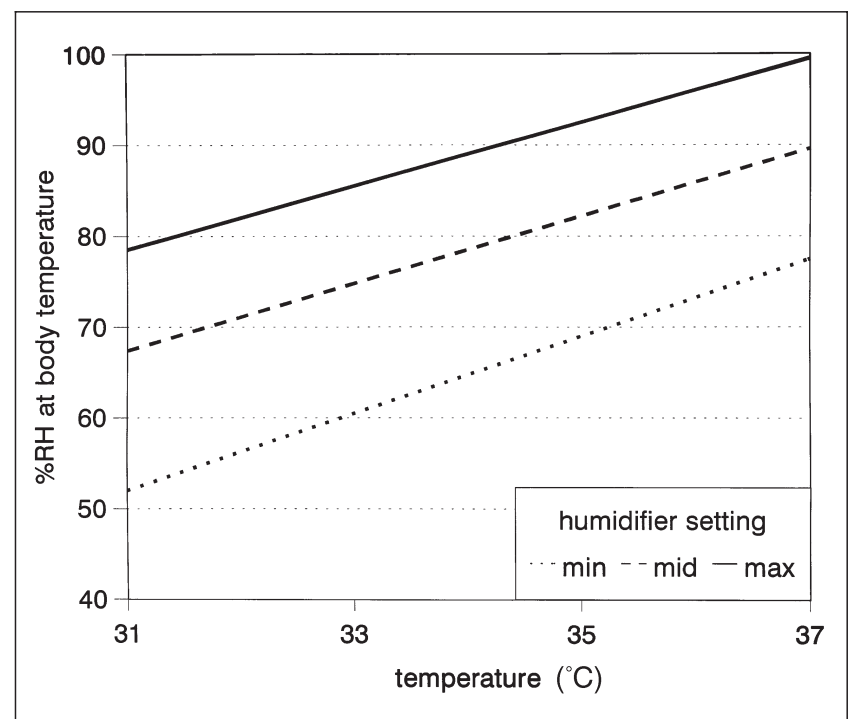

Figure 4) Effect of heated wire circuit on relative humidity $(R H)$ of inspired gas. Percentage RH at body temperature is shown for four proximal airway temperature settings and three humidity settings (min, mid, max). Note that the delivered humidity decreases with a lower temperature setting and a lower humidity setting on the humidifier. Data are pooled from four heated wire servo-controlled humidification systems. Data from reference 32

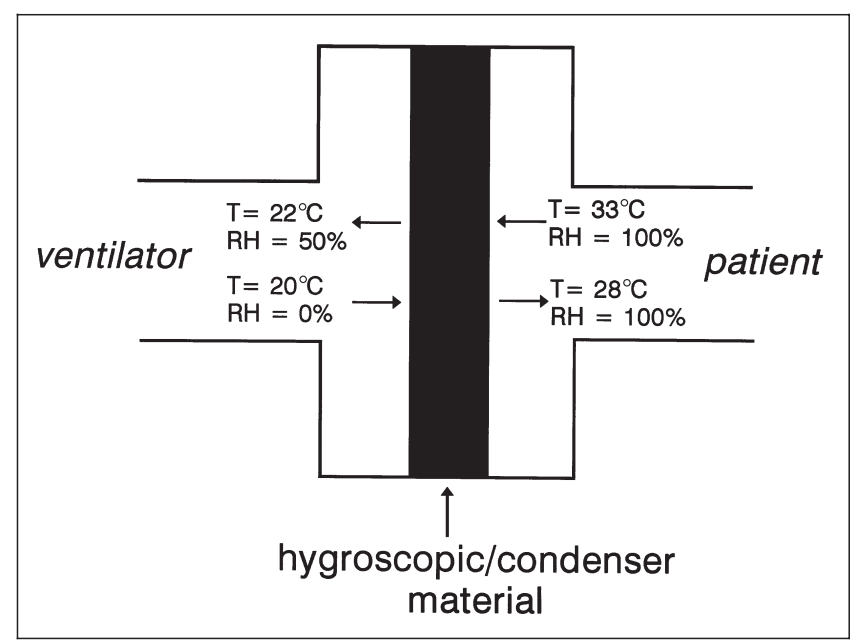

Figure 5) Schematic diagram of an artificial nose, showing the temperature $(T)$ and relative humidity $(R H)$ on the patient and ventilator sides of the device during inhalation and exhalation

$10 \mathrm{~L} / \mathrm{min}$. However, other devices perform poorly and should not be used - all artificial noses are not created equally. There is an increase in resistance to flow through these devices as they become saturated with water, increasing the work of breathing during spontaneous breathing. Although the most efficient devices provide greater than $30 \mathrm{mg} / \mathrm{L}$ of water, the output of artificial noses is less than that with a heated humidifier. When the artificial nose is used during prolonged mechanical ventilation, the patient must be frequently assessed for signs of inadequate humidification (eg, thick secretions, bronchial casts, mucus plugging). If signs of inadequate humidification are present, heated humidification 
TABLE 3

Contraindications to the use of artificial noses

Copious secretions

Secretions increase resistance to flow in the artificial nose. If a patient has copious amounts of secretions, the lack of therapeutic humidity may result in thickening of secretions when artificial noses are used

Very small or very large tidal volumes

With small tidal volumes, the dead space of the artificial nose may compromise ventilation and lead to $\mathrm{CO}_{2}$ retention. With large tidal volumes, the ability of the artificial nose to humidify inspired gases is compromised

Low synchronized intermittent mandatory ventilation rates and high spontaneous minute ventilation (>10 L/min)

Artificial noses should be used cautiously in patients with mandatory rates $\leq 4 / \mathrm{min}$. The resistance through artificial noses increases with time and makes spontaneous breathing difficult

Low ventilatory reserve with spontaneous breathing

The pressure drop required for flow through these devices may result in decreased breathing ability for patients who have low ventilatory reserves

Expired tidal volume $<70 \%$ of inspired tidal volume

To function properly, both inspired gases and expired gases must travel through the artificial nose

Hypothermia

Artificial noses are contraindicated with a body temperatures $<32^{\circ} \mathrm{C}$

Aerosol medication treatments

Artificial noses should be removed from the circuit during aerosol treatments when the nebulizer or inhaler is placed in the circuit

\section{TABLE 4}

Summary of published papers related to ventilator circuit change frequency

\section{Author, year (reference) Results}

Lareau et al, 1978 (23) No difference in VAP with 8, 16 and $24 \mathrm{~h}$ ventilator circuit changes

Craven et al, 1982 (12) No difference in ventilator circuit contamination with circuit changes at $24 \mathrm{~h}$ and $48 \mathrm{~h}$ intervals; contaminants in the circuits originated in the respiratory tracts of patients; water in cascade humidifiers remained sterile in spite of heavy circuit contamination near patient

Craven et al, 1986 (13) The odds of VAP were over two times greater when circuits were changed at $24 \mathrm{~h}$ rather than $48 \mathrm{~h}$ intervals Dreyfuss et al, 1991 (15) VAP rates were similar when circuits were changed every 48 h compared with no circuit changes; colonization of the circuit usually followed colonization of the pharynx and trachea; colonization of water in cascade humidifier was rare

Dreyfuss et al, 1995 (14) VAP rates were similar for use of heated humidifier use and artificial noses; no circuit changes in either group; results suggested that circuit colonization plays a small role in occurrence of VAP

Hess et al, 1995 (20) In a large study of more than 3000 patients and nearly 20,000 ventilator days, there was no significant difference in VAP with circuits changed at $48 \mathrm{~h}$ intervals and 7 day intervals

Kollef et al, 1995 (22) VAP rates were similar for 7 day circuit changes and no routine circuit changes

VAP Ventilator-associated pneumonia

should be initiated. The artificial nose should be replaced at $24 \mathrm{~h}$ intervals. There are clinical conditions that contraindicate the use of an artificial nose (Table 3).

\section{VENTILATOR CIRCUITS AND NOSOCOMIAL PNEUMONIA}

Intubated mechanically ventilated patients are at risk for nosocomial pneumonia. These pneumonias are associated with high morbidity and mortality, increased length of hospitalization and increased cost of care. The ventilator circuit has been historically associated with the risk of ventilatorassociated pneumonia (VAP). The condensate in mechanical ventilator circuits is often contaminated, raising the question as to whether this might pose a risk for VAP. It is now appreciated, however, that organisms contaminating the circuit usually originate from the patient. The patient contaminates the circuit, and VAP may not be ventilator-circuit related. VAPs are usually the result of aspiration of pharyngeal secretions and do not arise from the ventilator circuit. Ventilator circuits do not need to be changed more frequently than weekly for infection control purposes. Recently published papers have shown that the VAP rate does not increase when ventilator circuits are changed at weekly or less frequent intervals (Table 4), and the incidence of VAP may increase with more frequent circuit changes.

There are a number of issues related to ventilator circuits and the risk of VAP. Unlike wick humidifiers, cascade humidifiers produce microaerosols that can carry bacteria. However, humidifiers operate at a high temperature that is bactericidal for nosocomial pathogens. Heated circuits minimize condensation in ventilator circuits. Because circuit condensate almost always arises from the patient, the role of heated circuits to avoid VAP is unclear. For unheated circuits, water traps should be used and evacuated aseptically at regular intervals to avoid bolus lavage of the patient with circuit condensate. Artificial noses and heated circuits maintain a dry circuit, but have not been shown to affect the incidence of VAP. Use of medication nebulizers can deliver contaminated aerosols to the lower respiratory tract and metered dose inhalers may be superior to nebulizers in this 
respect. Closed suction systems may have useful infection control implications because they prevent spraying of ventilator circuit condensate and tracheal secretions into the intensive care environment during suctioning.

\section{BIBLIOGRAPHY}

1. AARC. Consensus statement on the essentials of mechanical ventilators - 1992. Respir Care 1992;37:1000-8

2. AARC Clinical Practice Guideline. Humidification during mechanical ventilation. Respir Care 1992;37:887-90.

3. AARC Clinical Practice Guideline. Patient-ventilator system checks. Respir Care 1992;37:882-6.

4. Ackerman MH. The effect of saline lavage prior to suctioning. Am J Crit Care 1993;2:326-30.

5. Banner MJ, Downs JB, Kirby RR, Smith RA, Boysen PG, Lampotang $\mathrm{S}$. Effects of expiratory flow resistance on inspiratory work of breathing. Chest 1988;93:795-9.

6. Bassin AS, Niederman MS. Prevention of ventilator-associated pneumonia. An attainable goal? Clin Chest Medicine 1995;16:195-208

7. Branson RD. Enhanced capabilities of current ICU ventilators: do they really benefit patients? Respir Care 1991;36:362-76.

8. Branson RD, Davis K, Campbell RS, Johnson DJ, Porembka DT. Humidification in the intensive care unit. Prospective study of a new protocol utilizing heated humidification and a hygroscopic condenser humidifier. Chest 1993;104:1800-5.

9. Branson RD, Hurst JM. Laboratory evaluation of moisture output of seven airway heat and moisture exchangers. Respir Care 1987;32:741-7.

10. Chatburn RL, Primiano FP. A rational basis for humidity therapy. Respir Care 1987;32:249-54.

11. Cobley M, Atkins M, Jones PL. Environmental contamination during tracheal suction. A comparison of disposable conventional catheters with a multiple-use closed system device. Anaesthesia 1991;46:957-61.

12. Craven DE, Connolly MG, Lichtenderg DA, Prineau PJ, McCabe WR. Contamination of mechanical ventilators with tubing changes every 24 or 48 hours. N Engl J Med 1982;306:1505-9.

13. Craven DE, Kunches LM, Kilisky V, Lichtenderg DA, Make BJ, McCabe WR. Risk factors for pneumonia and fatality in patients receiving continuous mechanical ventilation. Am Rev Respir Dis 1986;133:792-6.

14. Dreyfuss D, Djedaini K, Gros I, et al. Mechanical ventilation with heated humidifiers or heat and moisture exchangers: effects on patient colonization and incidence of nosocomial pneumonia. Am J Respir Crit Care Med 1995;151:986-92.

15. Dreyfuss D, Djedaini K, Weber P, et al. Prospective study of nosocomial pneumonia and of patient and circuit colonization during mechanical ventilation with circuit changes every 48 hours versus no change. Am Rev Respir Dis 1991;143:738-43.

16. George DL. Epidemiology of nosocomial pneumonia in intensive care unit patients. Clin Chest Medicine 1995;16:29-44.

17. Gilmour IJ, Boyle MJ, Rozenbery A, Palahniuk RJ. The effect of heated wire circuits on humidification of inspired gases. Anesth Analg 1994;79:160-4

18. Gilmour IJ, Boyle MJ, Streifel A, McComb RC. The effects of circuit and humidifier type on contamination potential during mechanical ventilation: a laboratory study. Am J Infect Control 1995;23:65-72.

19. Hess D. Guidelines for prevention of nosocomial pneumonia and ventilator circuits: time for a change? Respir Care 1994;39:1149-53.

20. Hess D, Burns E, Romagnoli D, Kacmarek RM. Weekly ventilator circuit changes. A strategy to reduce costs without affecting pneumonia rates. Anesthesiology 1995;82:903-11.

21. Hess D, McCurdy S, Simmons M. Compression volume in adult ventilator circuits: a comparison of five disposable circuits and a nondisposable circuit. Respir Care 1991;36:1113-8.

22. Kollef MH, Shapiro SD, Fraser VJ, et al. Mechanical ventilation with or without 7-day circuit changes. A randomized study. Ann Intern Med 1995;123:168-74.

23. Lareau SC, Ryan KJ, Diener CF. The relationship between frequency of ventilator circuit changes and infectious hazard. Am Rev Respir Dis 1978;118:493-6.

24. Manthous CA, Schmidt GA. Resistive pressure of a condenser humidifier in mechanically ventilated patients. Crit Care Med 1994;22:1792-5.

25. Marini JJ, Culver BH, Kirk W. Flow resistance of exhalation valves and positive end-expiratory pressure devices used in mechanical ventilation. Am Rev Respir Dis 1985;131:850-4.

26. Martin C, Papazian L, Perrin G, Sauz P, Gouin F. Preservation of humidity and heat of respiratory gases in patients with a minute ventilation greater than $10 \mathrm{~L} / \mathrm{min}$. Crit Care Med 1994;22:1871-6.

27. Miyao H, Hirokawa T, Miyasaka K, Kawazoe T. Relative humidity, not absolute humidity, is of great importance when using a humidifier with a heating wire. Crit Care Med 1992;20:674-9.

28. Nishimura M, Nishijima M, Okada T, Taenaka N, Yoshiya I. Comparison of flow-resistive work load due to humidifying devices. Chest 1990;97:600-4

29. Peterson B, Rankin N, Galler D. Temperature loss in dead space exposed to ambient air. Respir Care 1995;40:1164. (Abst)

30. Ploysongsang Y, Branson RD, Rashkin MC, Hurst JM. Effect of flowrate and duration of use on the pressure drop across six artificial noses. Respir Care 1989;34:902-7.

31. Shelly MP. Inspired gas conditioning. Respir Care 1992;37:1070-80.

32. Sullivan LM, Strong K, Trahey J, Hess D, Kacmarek RM. Relative humidity delivered by a neonatal heated wire circuit. Respir Care 1994;39:1104. (Abst) 


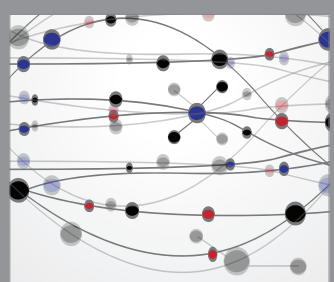

The Scientific World Journal
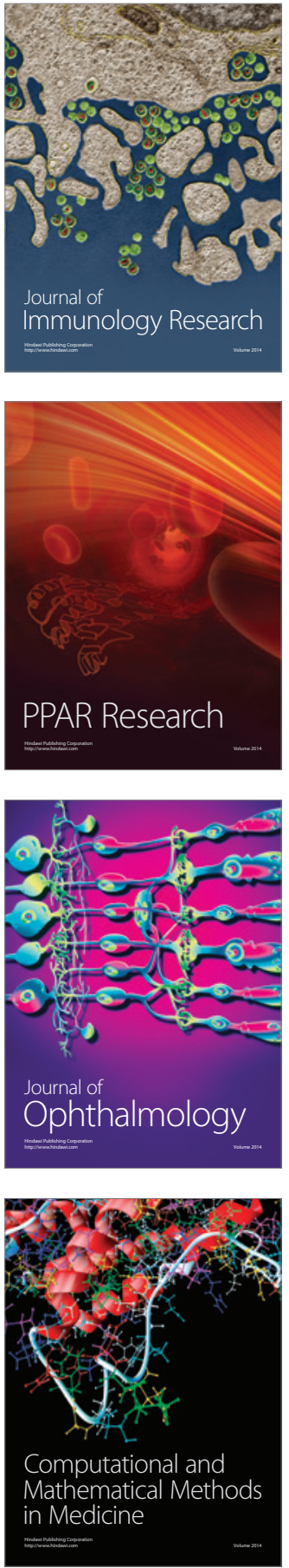

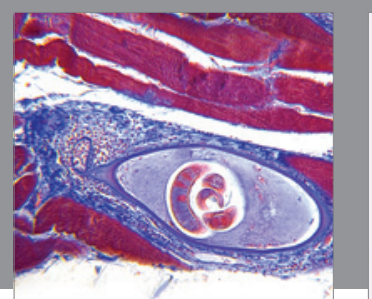

Gastroenterology Research and Practice

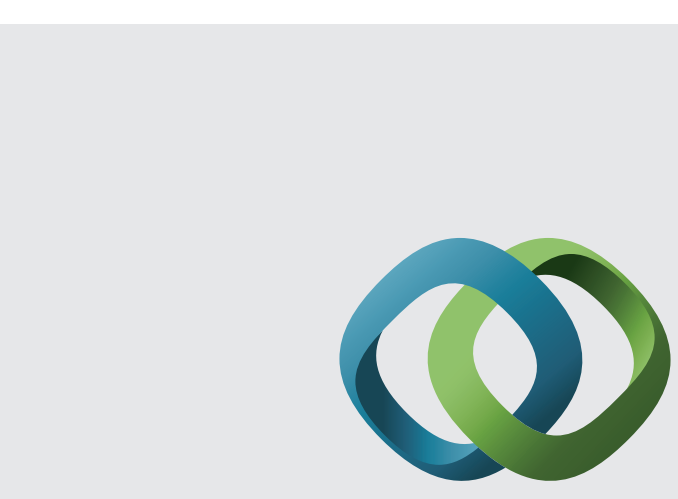

\section{Hindawi}

Submit your manuscripts at

http://www.hindawi.com
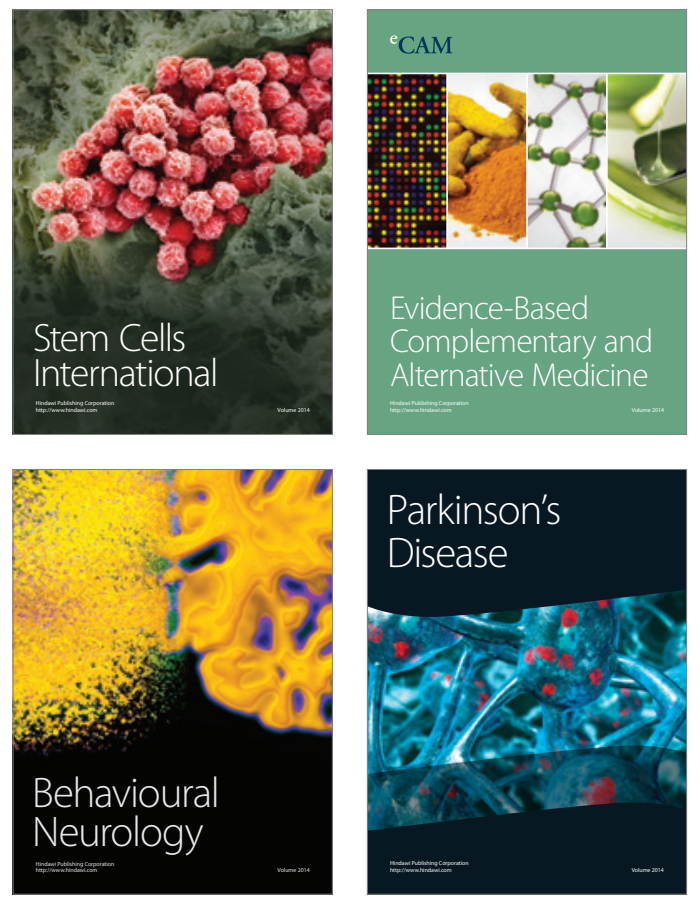
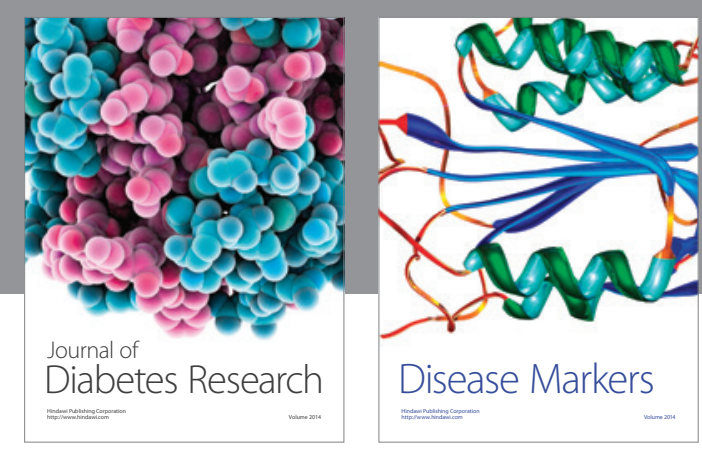

Disease Markers
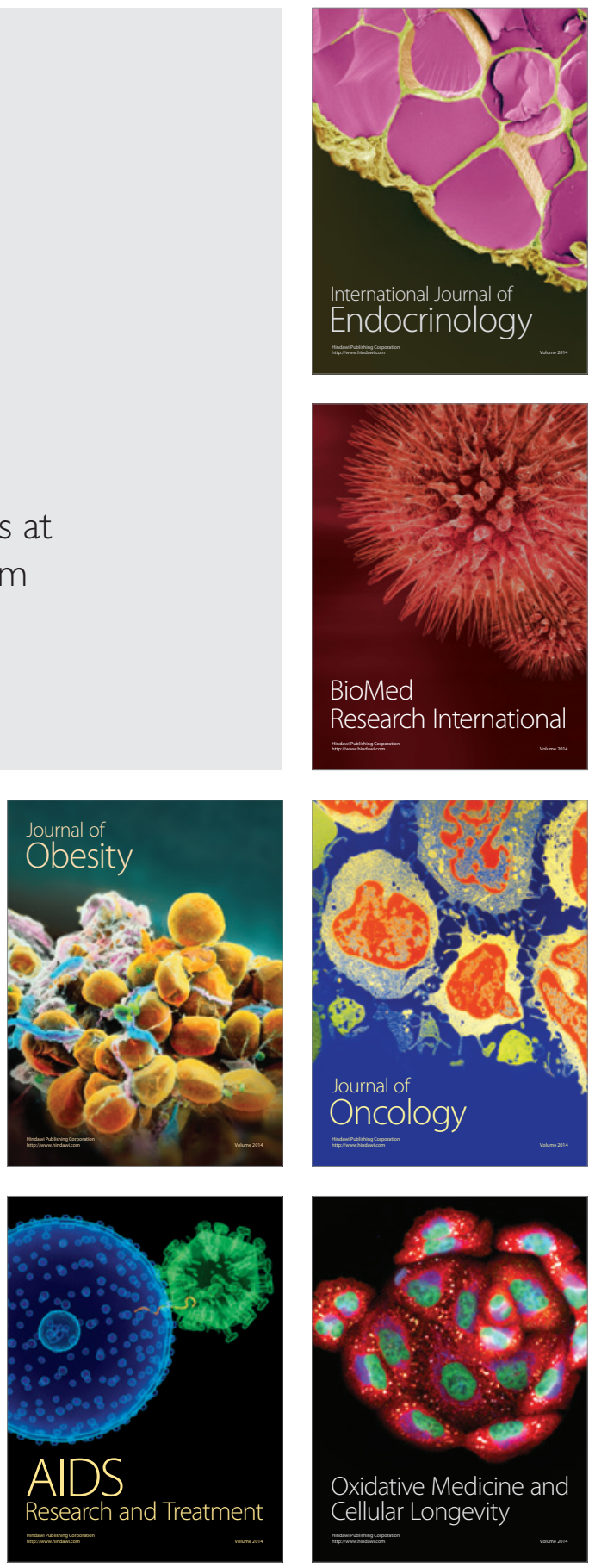